\title{
Ipsative learning: a personal approach to a student's experience of PBL within an integrated engineering design cornerstone module
}

\author{
Emanuela Tilley \\ University College London, United Kingdom \\ e.tilley@ucl.ac.uk \\ John E. Mitchell \\ University College London, United Kingdom \\ j.mitchell@ucl.ac.uk
}

\begin{abstract}
The Faculty of Engineering Science at University College London (UCL) has recently undergone a reform of the undergraduate curriculum, which resulted in the creation of a distinctive programme that connected curriculums from across seven engineering disciplines. The Integrated Engineering Programme is extensive, taking in nearly 700 students in its inaugural year at the start of the autumn 2014 term. Its most significant contributions are the experiential and authentic learning opportunities it provides students allowing them to apply their technical knowledge and develop their professional skills in engineering design modules year on year. The first opportunity for students to do this is within the cornerstone Integrated Engineering Design module in year I. This paper seeks to investigate the impact of an ipsative learning approach (feedback and assessment that is based on learner's progress) within this multidisciplinary problem/project-based learning environment (PBL/PjBL), which focuses learning outcomes on the student's ability to engage with the process of engineering design. The methods of conducting the research include the analysis of reflective writings by each student throughout the first of two 5-week 'Challenge' projects. A set of reflections written by each student was associated with two formative assessment meetings, referred to as Design Review Meetings, held with their academic leader. This data is also supplemented with verbal feedback provided by students and academics, which has been provided during follow up interviews and focus groups. Student self reflections written after each of the two meetings support common theses of increased understanding of the project aims and depth of student research efforts. Surprisingly, however is the evidence, which implies that an ipsative PBL environment empowers students to make critical personal and engineering decisions for effective progression within an engineering design project.
\end{abstract}

Keywords: Ipsative feedback, formative assessment, problem-based learning, engineering design

\section{INTRODUCTION}

Design is an increasingly important part of the engineering curriculum. Senior capstone projects have been a part of that experience for decades, but recently cornerstone and Problem- or Project-Based Learning (PBL/PjBL) have become more ubiquitous. The Faculty of Engineering Science at University College London (UCL) has recently undergone a reform of the undergraduate curriculum, which resulted in the creation of a distinctive programme, called the Integrated Engineering Programme (IEP) [1], which connects curriculums from across seven engineering disciplines. The programme introduces new interdisciplinary curriculum elements to each of the existing undergraduate degree programmes offered. Its most significant contributions are experiential and authentic learning opportunities that allow students to apply their technical knowledge and develop their professional skills in engineering design modules year on year. Spearheaded by the cornerstone Integrated Engineering Design (IE Design) year 1 module, UCL Engineering is moving towards a design-centred learning approach, by offering students a grounded learning experience in which knowledge is created through processes of divergent and convergent thinking as well as through independent research, critical analysis, making, testing and decisionmaking. The promising technique and characteristics of design-centred, experiential learning and the constructivist learning environments of $\mathrm{PBL} / \mathrm{PjBL}$ are, however, often plagued with complexities that can overwhelm learners. This paper presents evidence on how 
the inclusion of ipsative learning and assessment can help students deepen their engagement with the process of design and complex problem solving. Practical guidance on how ipsative assessment was embedded into the cornerstone engineering design module and reflections on how it was received by students is also provided. Our evidence suggests that timely formative assessment and feedback, which focuses on the learner's progress, as defined by an ipsative approach, can help to increase confidence and motivation levels; reduce cognitive load; and provide clarity, correction and direction whilst helping to improve the uptake of academic feedback.

Feedback is critical to improving knowledge and skill acquisition, whilst also providing students "with powerful messages about themselves as learners" [2]. According to Hattie and Timperley [3] feedback is one of the most powerful influences on learning and achievement and is a significant factor in motivating learning [4]. There is a growing concern in higher education institutions within the UK that the amount of summative assessment is too high [5] creating missed opportunities to enhance a student's learning experience through effective formative assessment and feedback. Hughes recounts "concern about assessment in many universities has not necessarily resulted in improvements in the all-important formative feedback given to students" [5]. Providing the most appropriate formative feedback methods - defined as information communicated to the learner that is intended to modify the learner's thinking or behavior for the purpose of improving learning, is not trivial.

Historical reviews of formative feedback over the past 50 years are characterized by constant debate, conflicting findings and little or no consistent pattern of results [6]. Shute believes that this could be attributed to the diversity that is deemed fundamental to its approach. Given that researchers in the area believe that formative feedback should be multidimensional, non-evaluative, supportive, timely, specific, credible, infrequent, and genuine it is hard to collect data that is comparable across programmes, let alone across disciplines [7,8].

Ipsative assessment is an assessment based on a learner's previous work rather than based on performance against external criteria and standards. Ipsative learning is perhaps more widely used in early education, rather than secondary or higher education (i.e. post-secondary education), as the focus on grades is often stressed over personal development. Another reason that could attribute to its limited use in higher education is the modularization of curriculum that doesn't allow for individual grade and feedback information to be shared across a degree programme to encourage the consideration of a learner's personal progression.

Ipsative feedback and assessment can be designed to include aspects of the 'good' feedback measures summarized by Shute and its structure should consist of comparative and developmental statements from assessors as well as self-assessment by learner(s). In this framework, its best feature is its motivational effect. It can help tackle de-motivating effects of failure and poor performance and increase learner's resilience. Hughes contests that ipsative assessment can enhance learner selfesteem, provide incentives to act on feedback by making feedback more useable and address both intrinsic and extrinsic motivation [5]. Student reflections of the ipsative feedback and formative assessment process included in the Integrated Engineering Design cornerstone PBL/PjBL module support this notion and are presented below.

The analogy often used to describe the ipsative approach is an achievement of a 'personal best' in athletics. Comparing existing and previous performance is often used in informal and practical learning experiences such as sport. The argument for introducing an ipsative approach to feedback within an academic setting is often presented as an alternative to criteria based assessment in order to give credit for how far a learner has advanced since the previous work. Positive recognition is often given when ipsative feedback is incorporated into formative assessment, however past studies have suggested that the connection to summative assessment is not fully recognized as the criteria are still seen by students as a transparent measure to pass or reach a graded level [5]. Confidence in the ipsative approach can be swayed by what is widely agreed upon by members of the academic community - summative assessment drives students by focusing tasks as well as time management, as it is what students pay most attention to [6]. Because of the complexities involved in teaching and assessing a 'formal' or academic discipline, criteria are recognized as being a set of descriptors essential to the learning experience. Using criteria as part of ipsative feedback can help to manage student grade expectations, an acknowledged drawback of the ipsative approach [5], and in fact help the students to better understand and engage with the set assessment criteria and learning outcomes. Accordingly, the simple ipsative question posed to teachers of 'How can we help students experience a personal best?' may be better suited in higher education, particularly in engineering and design-centred problembased modules, if it then becomes, 'What parts of the experience of getting a personal best can we give to our students to encourage and motivate them to reach the criteria we set?'.

Ipsative feedback can help students deepen their engagement with the process of design and complex problem solving by increasing personal confidence and motivation levels whilst providing clarity, correction and direction that clearly aligns with the set assessment criteria. Designers and design engineers, as well as those who research the process of design, continually describe design as a way of organizing complexity or finding clarity in chaos. 
The criteria were created to assess the students' ability to navigate and engage with the iterative process of engineering design in a PBL environment, particularly at the early stages where the research, creativity and communication are required to realize and isolate the problem; understand the needs of all stakeholders; investigate new cultures and technologies; and formulate and share ideas, before refining their chosen final solution. Three key practical elements, described in the remainder of this paper, aided in the successful application of ipsative feedback within a PBL module that was assessed using criteria as well- The ipsative elements were included specifically for the benefit of the students learning. They consisted of:

- Using scheduled class time to give feedback face to face, supported by written feedback provided by academics on draft submitted work;

- Connecting formative 'ipsative' feedback to the final summative assessment criteria; and

- Spending time on academic training, since the inclusion of formative feedback as part of a dialogue with students is a new experience for many and ipsative feedback is even more novel.

\section{INTEGRATED ENGINEERING DESIGN: UCL ENGINEERING'S CORNERSTONE DESIGN MODULE}

The IE Design module is intended to give the students an opportunity to put their learning into practice by working in an interdisciplinary, problem/project-based learning, industry linked and design focused environment. At its core, is the deliberate attempt to make use of and explore the creative and stimulating aspects of humancentred design as practiced by 'real' engineers and computer scientists in industry. This is highly supplemented by embedding the exploration and use of professional skills needed to be successful in the enticing and highly competitive working world.

The basic structure of the first term IE Design module consists of two 5-week 'Challenges', which have the students working in teams of mixed disciplines. The themes for the ill-defined problems, which form the basis of the two Challenges, are linked to such global challenges as sustainability and health. The learning objectives of the second Challenge build from those of the first. The first Challenge puts into practice the pedagogy of problem-based learning, whilst the second has a higher level of specification that aligns well with the principles of project-based learning [9]. The technical focus and level of difficulty also increases from the first to the second as the students in their first 5-weeks are bright, inquisitive, enthusiastic, high-achieving well versed in STEM subjects, but have little technical knowledge of their chosen engineering discipline. Upon completion of the full IE Design module, an initial sense of autonomy among the students is expected as they take responsibility for their own learning through their individual and team based experiences.

Both Challenges are presented to the teams of students with a human-centred design approach to problem solving in order for them to take into consideration stakeholder and user needs [10]. Students are given some experience and understanding of what it is like when they are accountable to actual stakeholders beyond the classroom. Including external community groups, cultural and industry partners as 'holders' of the Challenges that are presented to the students achieve this. Students are requested to identify and define the requirements, constraints and design parameters of their project, whilst engaging in research-led activities and self-study through enquiry-based learning. They are taught to explore the iterative processes of design and engineering thinking, whilst applying mathematics and engineering analysis to the development and creation of an integrated engineering solution. There is a focus in the first Challenge on the use of creativity to generate concepts, exercise critical thinking, implement a methodology to compare ideas and use engineering judgment to choose a final solution. Whereas, the second Challenge affords the student an opportunity to demonstrate knowledge and understanding of the equipment, materials and processes employed in the design, production and testing of integrated engineering systems, including specialized test and measurement equipment relevant to their chosen engineering discipline. The module's Challenges are supported through the integration and alignment of syllabuses with three other term 1 modules, which the students are concurrently enrolled to. These modules comprise Mathematical Modelling and Analysis, Design and Professional Skills and a technical introduction specific to their chosen discipline.

The assessment of student work varied between the two Challenges. Portfolios, a design solution video, team and client meetings, team and individual presentations, technical prototype performance testing and reflective writing comprised the body of work completed by the students for (formative and summative) assessment. In some instances these were designed to add an element of fun whilst others resemble authentic deliverables and experiences typically associated with the engineering profession. The summative assessment associated with the first Challenge was primarily based on the creation and collation of a digital portfolio throughout the five weeks and included collaborative teamwork as well individual aspects from each team member. A schedule of weekly milestones for the submission of draft work was given to the students from the module's onset. These strategically aligned with the planned ipsative feedback and formative assessment meetings between the academic leaders and student design teams. 


\subsection{Formative assessment 'Design Review Meetings'}

At two timely milestones within the first 5-week Challenge, meetings were scheduled between each of the student teams and their academic leader. The meetings occurred informally during the timetabled workshops, where the academic leader would move around from team to team within the two-hour regularly scheduled timeslot, sitting and conversing with the students. Students were given guidance notes ahead of the meetings, in order to understand how they were meant to prepare for the meeting and what draft portfolio work needed to be submitted online in advance. The meetings themselves were set out in a working-life setting, to mirror those in which engineers are called upon by a director or an external client to report details of their project work as well as update on progress. Students were asked to prepare and deliver a short presentation summarizing their work at the start of the meeting and then, the academic would follow up with their feedback and questions. The statements that were made by assessors were centred around the learner's progress whilst serving to provide the two main functions of formative feedback, direction and facilitation [11]. It was also intended to provide learners with the two key types of information, verification and elaboration, as reported by Kulhavy and Stock [12]. There is however an expectation set up with the students that they are to lead the meeting and that they should make the most of the meeting with the academic to clarify any misunderstandings or uncertainties they were encountering.

In the format of ipsative feedback and assessment, which consists of comparative and conditional or developmental statements from assessor as well as selfassessment by student [5], students and academics go into the design review meetings having assessed the submitted draft work. Both attend the meetings having completed an assessment with scoring centred around criteria taken from the final summative assessment rubric that is relevant to work completed in the Challenge thus far. A short conversation at the end of the meeting often involves dialogue that helps students understand how their own 'perceived' level of achievement aligns with that of the academic assessor. The full formative assessment session finishes with students going away and discussing the academic feedback amongst their teammates, often with a teaching assistant present, before completing a piece of individual reflective writing prompted by questions. Often this results in closing the gap between student and academic perceptions of quality of work and an increased understanding of the assessment criteria on behalf of the students, particularly during the second meeting. Below is a set of reflections completed by a student after the first and second meetings, when asked to write about the outcomes of the meeting as well as the ipsative feedback and assessment provided by the academic. The latter part of this student's reflection provides evidence that an ipsative PBL environment can empower students to make critical personal and engineering decisions for effective progression within their own engineering design project.

Meeting 1 student reflection: "The marks that I and my academic leader gave my team under each of the items in the Design Review Meeting \#1 Assessment Rubric are different. For instance, we gave ourselves quite high mark for stakeholders, and problem \& brief definition, but we only got $2 s$ for both criteria. I was surprised by the differences as I thought our team was doing a good job. I realized our team was falling behind based on the criteria in those categories of the assessment. In order to get high marks, we must improve a lot to get back on track. Our academic leader thought we have done a very great job on the presentation during the meeting. But for some reasons, some of the content of the presentation is missing in the team portfolio. So, we have to figure out what we can do to make it better based on how we prepared for the meeting. When I self-evaluated it, I realized it is a bit unorganised and rather long in content. To improve the quality of it, I should cut down the content and make it more precise".

Meeting 2 student reflection: "The marks that each of us gave to ourselves, are quite similar to the ones given by our academic leader. This means we have a better understanding of what quality and kind of work will end up getting us a good mark on the project, compared to our first Design Review Meeting."

Discussions with students in focus groups afterwards as well as individual reflections submitted indicate student confidence levels can be negatively affected at the first meeting, but the criteria based ipsative feedback increases student motivation to engage further with the project. After the second, many students feel a real sense of achievement when progress is acknowledged and their self-assessments are much more closely matched to that of the academic. Having two of these meetings gives academics an opportunity to provide an ipsative learning experience to their students.

Another student reflected on how the focus of the feedback was on improving the individual skill sets of students that are critical to successful engineering design and improvement in the quality of their team project.

\footnotetext{
"The following are the lessons I learned from our meeting with our academic leader:

- To not give information we cannot back up with facts and correct statistics.
} 
- We need to do more research into the stakeholders (people affected by this project e.g. miming companies) of this project and how are they affected.

- We need to understand what sustainability is properly, however we were told that we did a great job summarizing the initial research provided.

- $\quad$ Our arguments need to be more technical and very detailed.

- We need to find out answers to some very detailed questions like, 'How much do these people earn?' and 'How much energy is used in schools, by females, males and children?'.

- If we don't know something we should not assume but be honest and say that 'we do not know etc.... and we need to find out."

Ipsative feedback and assessment can address the 'feedback is only useful if the task is repeated' argument that is often raised in discussions regarding the effectiveness of feedback. The student reflection provided gives an early indication of potential conceptual and skill based links that should be emphasized and supported across programmes in modularized curriculums through feed forward and acknowledgement of progress made on past performances. This however is very difficult to implement practically, however the Engineering faculty at UCL are committed to developing new administrative and online systems to support a connected curriculum that enables the collation of feedback and grades for each student to be kept as a personal record and shared with their personal tutors.

Ipsative feedback can add to what is missing in many PBL / authentic learning assessment methods. A group of academics from Aston University in Birmingham, UK who led recent curriculum reforms that introduced CDIO across the first year undergraduate curriculum in the department of Mechanical Engineering and Design, have highlighted that even widely practiced methods of PBL still struggle to provide adequate assessment and feedback, particularly in the provision of individual feedback. The content of the student reflections lends support to the notion that in PBL, facilitation helps to build confidence and spark motivation in students to further explore their research and go into added depth with their ideas and concepts than if left without. Moreover, the academic will expect the student to formulate an opinion, gather evidence to provide a supporting technical argument and make decisions on matters that perhaps they would not have, if not challenged to do so. These meetings have highlighted the importance of having the students experience some degree of failure and understand that such difficult experiences can be beneficial to their learning and future achievements. Adding an element of ipsative feedback to the facilitation provided by the academic can help the student more readily make such personal realizations.

\section{CONCLUSIONS}

Cornerstone engineering design modules form the basis for all future project based modules. This is influential as conceptual tasks can be repeated and skill sets developed. These modules provide students with an opportunity to understand and realise very early on in their engineering education that there are plenty of opportunities to benefit from the feedback and lessons learned. A significant conclusion to report is the capacity for ipsative feedback and assessment to increase the effectiveness of formative feedback, particularly in criteria based engineering design modules, where students are often put into teams and assessed on how they work through the creative yet iterative design process that has them ultimately establish a solution to a given problem that they deem as optimal. The ipsative approach supports the student centred teaching and learning methods of PBL pedagogy whilst valuing learner progress. Student self reflections written after each of the two design review meetings support common theses of increased confidence and motivation levels, depth of research efforts and understanding of the project aims and assessment criteria. There is even evidence, which implies that an ipsative PBL environment empowers students to make critical personal and engineering decisions for effective progression within their own engineering design project.

The experience of providing face-to-face formative feedback sessions, as part of the scheduled review meetings, has highlighted some issues surrounding the practical implementation of ipsative feedback. Both students and academics need to be fully committed to the set (formative and summative) assessment schedule. Meaning, the students need to see the benefit in submitting draft work for the academics to give feedback on and the academics need to be comfortable with giving feedback on progress, not just criteria based content, in live meetings with students through dialogue. For the students, it is essential that the ipsative feedback and formative assessment is clearly linked to the summative assessment. For the academics, this requires the provision of training and practice opportunities. Further operational support is needed within departments and/or faculties and across degree programmes to provide opportunities to collate, connect and share with personal tutors, individual student grades and feedback between modules and degree years to promote feed forward opportunities and acknowledge progress made on past performances. 


\section{References}

[1] Mitchell, J. E., Bains, S., Nyamapfene, A., and Tilley, E. (2015), Work in Progress: Multi-disciplinary curriculum review of Engineering Education. UCL's Integrated Engineering Programme, Proc. of the IEEE EDUCON 2015 Conference, IEEE, Estonia.

[2] Stobart, G. (2008) Testing Times: The uses and abuses of assessment. Abingdon, Routledge

[3] Hattie, J., \& Timperley, H. (2007). The power of feedback. Review of Educational Research, 77, 81-112.

[4] Hattie, J. (2009). Visible learning. A synthesis of over 800 meta-analyses relating to achievement. London: Rouledge.

[5] Hughes, G. (2011). Towards a personal best: a case for introducing ipsative assessment in higher education. Studies in Higher Education, 36(3), 353-367. doi: $10.1080 / 03075079.2010 .486859$

[6] Shute, V. J. (2006). Assessments for learning: Great idea, but do they work? Paper presented at the annual meeting of the American Educational Research Association, San Francisco, CA.

[7] Schwartz, F., \& White, K. (2000). Making sense of it all: Giving and getting online course feedback. In K. W. White \& B. H. Weight (Eds.), The online teaching guide: A handbook of attitudes, strategies, and techniques for the virtual classroom (pp. 57-72). Boston: Allyn and Bacon.

[8] Brophy, J. E. (1981). Teacher praise: A functional analysis. Review of Educational Research, 51(1), 5-32.

[9] Savin Badin, M., Howell Major, C. (2004), Foundations of Problem-based Learning, The Society for Research into Higher Education, Open University Press, McGraw-Hill Education, Maidenhead.

[10] IDEO. Human-Centred Design Toolkit, 2nd Edition [internet]. Seattle: Bill \& Melinda Gates Foundation. [cited 2014 July]. Available from: http://d1r3w4d5z5a88i.cloudfront.net/assets/toolkit/IDEO.or g_HCD_ToolKit_English5fef26ba5fa5761a3b021057d1d4a851.pdf

[11] Black, P., \& Wiliam, D. (1998). Assessment and classroom learning. Assessment in Education: Principles, Policy \& Practice, 5(1), 7-74.

[12] Kulhavy, R. W., \& Stock, W. (1989). Feedback in written instruction: The place of response certitude. Educational Psychology Review, 1(4), 279-308. 